\title{
Syncope due to third-degree atrioventricular block as the only manifestation of myocarditis following COVID-19 infection
}

\author{
Katarzyna Wojewoda' ${ }^{1,2}$, Adam Tarkowski', Katarzyna Wysokinska' ${ }^{1,2}$, Mariusz Kozak', Marcin Janowski', Jacek \\ Baszak', Piotr Waciński', Andrzej Wysokinski ${ }^{1}$, Andrzej Głowniak ${ }^{1}$
}

'Department of Cardiology, Medical University of Lublin, Lublin, Poland

${ }^{2}$ Doctoral School, Medical University of Lublin, Lublin, Poland

\author{
Correspondence to: \\ Andrzej Głowniak, MD, PhD, \\ Department of Cardiology, \\ Medical University of Lublin, \\ Jaczewskiego 8, 20-954 Lublin, \\ Poland, \\ phone: +48 7244151 , \\ e-mail: \\ andrzej.glowniak@gmail.com \\ Copyright by the Author(s), 2021 \\ Kardiol Pol. 2021; \\ 79 (11): 1296-1297; \\ DOI: 10.33963/KP.a2021.0117 \\ Received: \\ August 23, 2021 \\ Revision accepted: \\ September 22, 2021 \\ Published online: \\ September 22, 2021
}

The SARS-CoV-2 infection results in respiratory distress as the major manifestation, though there are also well-documented cardiac complications. COVID-19 associated atrial tachyarrhythmias are mostly described, and high-degree conduction disturbances are less common [1]. We describe a case of a patient without prior cardiovascular history nor structural cardiac abnormalities who developed symptomatic complete atrioventricular block (CAVB) after mild COVID-19.

A 52-year-old female was admitted to the emergency room after the loss of consciousness. Seven days earlier she was released from home quarantine due to COVID-19, which manifested with fatigue, headache, and fever. A pre-admission computed tomography scan of the chest disclosed ground-glass opacities, representative of resolving COVID-19. On admission, her heart rate was $38 \mathrm{bpm}$ with blood pressure 100/70 mm Hg. The electrocardiogram (Figure 1A) showed CAVB. There were no abnormalities in the laboratory test results except for troponin I and D-dimer levels, elevated to $5575 \mathrm{ng} / \mathrm{l}$ and $6301 \mathrm{ng} / \mathrm{ml}$, respectively. A transthoracic echocardiogram demonstrated pericardial effusion $(7 \mathrm{~mm})$, normal ejection fraction, and no structural abnormalities. Considering symptoms, transvenous temporary cardiac pacing was inserted. Coronary angiography was normal and computed tomography pulmonary angiogram excluded pulmonary embolism. On the second day, CAVB resolved spontaneously, and the next day, the temporary pacing lead was removed. Additionally, the patient was treated with levofloxacin and enoxaparin, switched subsequently to acetylsalicylic acid. No arrhythmias nor conduction disorders were registered by means of 3-day Holter monitoring, and the patient remained symptomless. Considering the history of syncope, an electrophysiological study was performed on the $14^{\text {th }}$ day post-admission, revealing normal atrioventricular conduction parameters (Figure 1B). On the day of discharge, there was no fluid in the pericardium on control echocardiography. The patient was discharged home on the $19^{\text {th }}$ day. 24-hour Holter monitoring performed at one-month follow-up revealed normal AV conduction.

To the best of our knowledge, this is the first reported case of symptomatic high-degree atrioventricular block during COVID-19 recovery. Only a few papers have reported high-degree atrioventricular block (AVB) in the course of symptomatic SARS-CoV-2 infection but not in the post-COVID-19 convalescents [1-3]. In the several COVID-19-related AV conduction disorders reported so far, QRS complex morphology suggested proximal AVB location, and varying degrees of AVB were treated conservatively $[2,5]$, except for one case of preventive pacemaker implantation [3].

There are several possible mechanisms of cardiac damage in COVID-19, including hypoxemia, coronary artery thrombosis, and cytokine-storm-related cardiac involvement, and cases of post-COVID-19 severe fulminant myocarditis were described [4]. Considering elevated myocardial injury markers, the most 




Figure 1. Electrocardiogram demonstrating third-degree atrioventricular block with a heart rate of $41 \mathrm{bpm}$ at admission (A) the electrophysiology study performed before the discharge proving normal A-H-V conduction intervals (B) and the troponin, CRP, and D-dimer levels change in time with the duration of AV block indicated (C)

Abbreviations: CRP, C-reactive protein

probable cause of CAVB in the presented case was subclinical myocarditis.

Though the occurrence of CAVB associated with viral infection is rare, this case demonstrates the possible risk of AV conduction disorders in otherwise asymptomatic patients with a benign course of COVID-19. Moreover, the development of the cardiac conduction system disease in patients convalescing from COVID-19 should raise awareness about cardiovascular complications in patients infected with SARS-CoV-2 as well as the potential long-term outcome of COVID-19. Although the spontaneous resolution of AVB in our patient and a few previously reported cases suggests the transient nature of disorders, a closer follow-up with electrocardiogram monitoring should be recommended in post-COVID-19 patients with elevated troponin levels.

\section{Article information}

Conflict of interests: None declared.

Open access: This article is available in open access under Creative Common Attribution-Non-Commercial-No Derivatives 4.0 International (CC BY-NC-ND 4.0) license, allowing to download articles and share them with others as long as they credit the authors and the publisher, but without permission to change them in any way or use them commercially. For commercial use, please contact the journal office at kardiologiapolska@ptkardio.pl.
How to cite: Wojewoda K, Tarkowski A, Wysokinska K, et al. Syncope due to third-degree atrioventricular block as the only manifestation of myocarditis following COVID-19 infection. Kardiol Pol. 2021; 79(11): 1296-1297, doi: 10.33963/KP.a2021.0117.

\section{REFERENCES}

1. Coromilas EJ, Kochav S, Goldenthal I, et al. Worldwide survey of COVID-19-associated arrhythmias. Circ Arrhythm Electrophysiol. 2021; 14(3): e009458, doi: 10.1161/CIRCEP.120.009458, indexed in Pubmed: 33554620.

2. Babapoor-Farrokhran S, Batnyam U, Wiener PC, et al. Atrioventricular and sinus node dysfunction in stable COVID-19 patients. SN Compr Clin Med. 2020 [Epub ahead of print]: 1-4, doi: 10.1007/s42399-020-00497-5, indexed in Pubmed: 32901230.

3. Al-Assaf O, Mirza M, Musa A. Atypical presentation of COVID-19 as subclinical myocarditis with persistent high-degree atrioventricular block treated with pacemaker implant. HeartRhythm Case Rep. 2020; 6(11): 884-887, doi: 10.1016/j.hrcr.2020.09.003, indexed in Pubmed: 32953452.

4. Marcinkiewicz K, Petryka-Mazurkiewicz J, Nowicki MM, et al. Acute heart failure in the course of fulminant myocarditis requiring mechanical circulatory support in a healthy young patient after coronavirus disease 2019. Kardiol Pol. 2021; 79(5): 583-584, doi: 10.33963/KP.15888, indexed in Pubmed: 34125938.

5. Eneizat Mahdawi $\mathrm{T}$, Wang $\mathrm{H}, \mathrm{Haddadin} \mathrm{Fl}$, et al. Heart block in patients with coronavirus disease 2019: a case series of 3 patients infected with SARS-CoV-2. HeartRhythm Case Rep. 2020; 6(9): 652-656, doi: 10.1016/j. hrcr.2020.06.014, indexed in Pubmed: 32837907. 